\begin{abstract}
Iranica
Abstracta Iranica Revue bibliographique pour le domaine irano-aryen

Volume 32-33 | 2013

Comptes rendus des publications de 2009-2010

\section{John Baily. The Art of the 'Fieldwork Movie': 35 Years of Making Ethnomusicological Films}

Ariane Zevaco

\title{
OpenEdition
}

\section{Édition électronique}

URL : http://journals.openedition.org/abstractairanica/40159

DOI : 10.4000/abstractairanica.40159

ISSN : 1961-960X

Éditeur :

CNRS (UMR 7528 Mondes iraniens et indiens), Éditions de l'IFRI

\section{Édition imprimée}

Date de publication : 1 décembre 2013

ISSN : 0240-8910

\section{Référence électronique}

Ariane Zevaco, « John Baily. The Art of the 'Fieldwork Movie': 35 Years of Making Ethnomusicological Films ", Abstracta Iranica [En ligne], Volume 32-33 | 2013, document 470, mis en ligne le 01 juillet 2016, consulté le 26 septembre 2020. URL : http://journals.openedition.org/abstractairanica/40159; DOI : https://doi.org/10.4000/abstractairanica.40159

Ce document a été généré automatiquement le 26 septembre 2020.

Tous droits réservés 


\title{
John Baily. The Art of the 'Fieldwork Movie': 35 Years of Making Ethnomusicological Films
}

\author{
Ariane Zevaco
}

\section{RÉFÉRENCE}

John Baily. « The Art of the 'Fieldwork Movie': 35 Years of Making Ethnomusicological

Films ». Ethnomusicology Forum, vol. 18, n 1, 2009, p. 55-64.

1 Dans ce court article, John Baily, ethnomusicologue britannique connu pour ses recherches sur les musiques d'Afghanistan, revient sur ses réalisations cinématographiques, menées en tandem avec ses recherches, depuis les années 1970. Il raconte son parcours d'apprentissage filmique, soulignant l'évolution du matériel et ses conséquences sur le travail sonore des films.

2 Baily a commencé par utiliser le film comme manière de récolter des données, en complément exhaustif du carnet de terrain d'un ethnologue. Il s'en servit d'abord pour filmer les gestes de la musique du dotar à Herat, puis de façon plus large pour «documenter la performance musicale en contexte» (p. 56), et la vie en général à Herat ; un travail qu'il édita ensuite sous la forme de trois films.

3 Son apprentissage de la réalisation de film documentaire, au sein des principales institutions du film documentaire en Grande-Bretagne, et sous la direction de Paul Henley, est largement détaillé. John Baily se situe dans le courant de l'«observational cinema », différent du " cinéma direct » en ce qu'il est envisagé selon lui comme « more concerned with the detailed observation of everyday life » (p. 57). Il cherche donc à voir les choses davantage du point de vue des sujets qu'il filme, sans occulter l'impact de sa présence en tant que réalisateur sur les situations et activités filmées.

4 C'est après ses études cinématographiques qu'il réalise Amir: An Afghan Refugee Musician's Life in Peshawar, Pakistan (1985), une expérience qui marque un tournant dans 
son utilisation de la caméra autant que dans ses recherches en ethnomusicologie, puisqu'il initie alors son travail sur les musiciens afghans en diaspora. Dans les années 2000, il produit quatre films sur la musique en exil, qu'il qualifie davantage de «fieldwork movies ", accompagnant un travail ethnologique plutôt que, à l'instar d' Amir, constituant un film motivé d'abord par la volonté de réaliser un film documentaire.

5 Sa vision de l'activité filmique est celle d'un travail commun avec ses amis afghans, fait en confiance et en prenant en compte le point de vue, les remarques et désirs des sujets qu'il filme. Il souligne pour finir la valeur de document de ses films, dont il espère qu'ils pourront renseigner les futures générations d'Afghans sur la vie musicale.

6 John Baily livre ici d'importantes clés ouvrant non seulement sur la question de l'importance du film ethnologique en tant que document, mais aussi sur la difficulté à filmer la musique. Ce faisant, il rappelle les principes de l'observation de terrain en anthropologie, loin des édifices théoriques qui peuvent éloigner le chercheur de la réalité ethnographique.

\section{AUTEURS}

ARIANE ZEVACO

Paris 